\title{
Pregnancy gone wrong: Women's experiences of care in relation to coping with a medical complication in pregnancy
}

\author{
Jane Currie ${ }^{A, B}$ MSSC, Carrie Cornsweet Barber ${ }^{B}, \mathrm{PhD}$
}

${ }^{\text {A }}$ Corresponding Author: jchc1@ students.waikato. ac.nz

${ }^{\mathrm{B}}$ University of Waikato, New Zealand

\begin{abstract}
:
Objective: To understand the experiences of twelve New Zealand women with medical complications in pregnancy.

Method: Inductive, semantic, qualitative analysis was employed to obtain an in-depth insight into the experience of having a medical complication during pregnancy. Semi-structured interviews were conducted face-to-face with twelve women. Six had been hospitalised during their pregnancy, while a further six were recruited from outpatient settings.

Findings: Five themes were identified: pregnancy distressing and overshadowed by complications; unpredictability and the need for control; importance of the relationship with midwives; disempowerment in hospital; and lessons learnt on the importance of support.

Key conclusions: Medical complications during pregnancy can be extremely stressful and women feel particularly vulnerable during this time. Midwives play a key role in supporting women through the process of coping with a pregnancy marked by illness and uncertainty.

Implications for practice: Midwives can play a unique role in translating medical jargon and providing emotional guidance and support. A midwife who is engaged and responsive to a woman's needs has the ability to lower distress at this critical juncture in the development of a woman and her family.
\end{abstract}

Keywords: Pregnancy, health perceptions, stress, anxiety, hospitalisation and relationships with midwives.

\section{INTRODUCTION}

There has been increasing recognition of the physical and psychosocial effects of stress, anxiety and depression during pregnancy, both on the fetus and on the mother (Dunkel Schetter \& Tanner, 2012; Heaman, Gupton, \& Gregory, 2004). When there is a health threat during pregnancy, either to the pregnant woman or to her fetus, a growing body of literature suggests that these pregnant women are at increased risk of experiencing psychological distress during and after pregnancy (Barber \& Starkey, 2015; Brandon, Pitts, Robinson, \& Stringer, 2007; Brandon et al., 2008; Breitkopf et al., 2006; Da Costa, Larouche, Dritsa, \& Brender, 1999; Robinson, Pennell, McLeane, Oddy, \& Newnham, 2011). Research suggests that mothers' stress hormones can have a direct effect on the fetus, affecting the development of the nervous system and brain, associated with an increased risk of later childhood problems, such as learning difficulties and disruptions in emotional development (Dunkel Schetter, 2009; Dunkel Schetter \& Tanner, 2012). Distress during pregnancy has also been shown to be a significant predictor of labour difficulties and preterm birth (Littleton, Bye, Buck, \& Amacker, 2010). Anxiety and stress in pregnancy have been shown to increase risk of postnatal depression and postnatal anxiety, which in turn can influence maternal-child attachment (Brandon et al., 2008).

Primary maternity care in New Zealand is provided by Lead Maternity Carers (LMCs), who are selected by women to provide their lead maternity care. LMCs can be midwives, general practitioners (GPs), or obstetricians. LMCs are responsible for the care provided to women throughout their pregnancy and up to six weeks following the birth. New Zealand maternity services are integrated, with LMCs being able to access any necessary additional services such as obstetric or paediatric care for their clients. LMCs remain responsible for overall coordination of the care, even if clinical responsibility of that care transfers from one practitioner to another for a time. If there is a need for secondary or tertiary care during the pregnancy or labour and birth, it is provided, but the woman would return to the care of her LMC for the duration of the pregnancy and/or postnatal care (New Zealand College of Midwives Inc., 2016).

A recent New Zealand study found that approximately 37\% of pregnant women were referred by midwives to other health professionals for medical issues arising during pregnancy (Skinner, 2011). In an international study, it was estimated that nearly $20 \%$ of all pregnant women are hospitalised during pregnancy (Gray, 2006). Some of the most common fears associated with pregnancy are those to do with the health of the baby (Melender \& Lauri, 1999). Medically complicated and/or high-risk pregnancies have been shown to be anxiety provoking and increase the likelihood of depression as well as causing stress and distress (Barber \& Starkey, 2015; Dunkel Schetter \& Tanner, 2012; King et al., 2010; Leeners et al., 2008; Leichtentritt, Blumenthal, Elyassi, \& Rotmensch, 
2005; Perlen, Woolhouse, Gartland, \& Brown, 2013; Stainton, Lohan, \& Woodhart, 2005).

Research has identified anxiety and stress around medical complications as an important clinical issue. However, the literature has not fully explored the experience of women with medical complications, and the factors that they identify as important to their wellbeing. The present study sought to understand the experience of pregnancy complications among New Zealand women and to explore how they perceive their illness and cope with its challenges and treatment.

\section{METHOD}

The research used semi-structured interviews with pregnant women who had been diagnosed with a medical complication. Twelve women with a wide range of experiences were interviewed. Six women volunteered in response to an invitation sent out as a part of a follow-up of women who had participated in a study almost two years previously, during a prenatal hospital stay. Six additional women were recruited via midwives and media sites; these women were pregnant and had been diagnosed with a medical problem at the time of the interview.

The study was reviewed and approved by the University of Waikato School of Psychology Research and Ethics Committee. Written consent to participate was attained prior to each interview and questions were also introduced in such a way so that the women could decide to decline to answer. Eight of the women were New Zealand European (NZE), two were Indian, one was English and one was Mãori/NZE. Ages ranged from 23 to 40. For four of the participants, this was the first pregnancy; five of the participants had experienced miscarriages before the current pregnancy, and three had delivered a premature baby previously. Medical complications included gestational diabetes (3), high blood pressure (2), maternal heart condition (1), slow fetal growth (2), incompetent cervix (2), carpel tunnel syndrome (1), low blood pressure (1), placental abruption (1), potential preterm delivery (3), pre-eclampsia (1) and hyperemesis (2). Eight of the women had more than one complication.

\section{The words women used included 'fear', 'painful', 'a bit traumatic' and 'a shock'. This suggested that the normal experience of pregnancy was interrupted by the complication and the medical care and monitoring associated with it.}

The audio-recorded interviews were transcribed and a pseudonym was allocated to each woman. Thematic analysis was applied which was inductive (no theoretical underpinnings) and semantic (explicit) to discover underlying themes. Semantic, inductive, thematic analysis was used because it reduces the risk that the researchers' preconceived ideas about the topic would influence the findings (Braun \& Clarke, 2006). It does this by taking the words used by the interviewees at face value enabling researchers to generate unanticipated insights. It also enables researchers to usefully summarise a large amount of data, such as is obtained during hour-long verbal interviews (Braun \& Clarke, 2006).

\section{FINDINGS}

Through thematic analysis, five themes were identified which identified the key points and summarised the interviews with the twelve women. These included:

\section{1) Pregnancy distressing and overshadowed by complications}

Ten of the twelve women described their overall pregnancy using words that depict high levels of distress. The words women used included "fear", "painful", "a bit traumatic" and "a shock". This suggested that the normal experience of pregnancy was interrupted by the complication and the medical care and monitoring associated with it.

\section{"Before this pregnancy with the twins, I had three miscarriages, so you know when women are pregnant they are just so over the moon. It was just full of fear, that was what it was, to get to the eight-week mark and bleeding. So I think it was fear" (Mary, potential preterm delivery). \\ "I basically live in fear every day of losing this baby even so far everything is going really well. It is, I know, on the back of my mind; it is things can go wrong overnight" (Trish, incompetent cervix).}

\section{This intense emotional distress, feeling the need to contain and restrict emotions, and pervasive fear appear to be responses to emotional trauma, and clearly affected women for months and years afterward and is ongoing.}

The emotional impact of these experiences was evident; each of the women who had been hospitalised and was reflecting back on her past pregnancy, cried during the interview. Those who were currently pregnant described their distress, but were more controlled in their emotional expression, and none shed tears during the interview. All of the women looking back on their distress described controlling their emotional expression at the time, holding it together for the sake of others:

\section{"I suppressed my feeling when I saw my husband's face. I didn't cry I just held my emotions in" (Cherie, placental abruption).}

This intense emotional distress, feeling the need to contain and restrict emotions, and pervasive fear appear to be responses to emotional trauma, and clearly affected women for months and years afterward and are ongoing.

\section{2) Loss of control and unpredictability}

When participants were diagnosed with a serious complication and/or hospitalised, all twelve women described feeling out of control, helpless, and out of their depth.

"Oh so out of control. I have never seen my husband so white. I was so overwhelmed. Completely overwhelmed" (Mary, potential preterm delivery).

"Oh so out of control. I was so overwhelmed. The moment of feeling completely out of your depth hit a thousand fold" (Ana, high blood pressure).

This feeling of helplessness is important; feeling disempowered and out of control magnifies the impact of stress, and leaves 
women vulnerable to depression (Barber, 2012). It is striking that all of the participants expressed these feelings, triggered by the unexpected and unwanted plunge into the world of medical management and the discourse of risk.

Unpredictability was described by all participants, but women who had a complication with a lack of observable symptoms, such as high blood pressure, described how this unpredictability created additional distress:

\begin{abstract}
"Having no symptoms made it worse-I felt more at risk as I didn't know what I was reacting to" (Jennifer, high blood pressure/potential preterm delivery).
\end{abstract}

"Felt like a fraud-I did not know how to react as I did not feel as if I was having a complication" (Ana, high blood pressure).

The experience of not knowing whether you are well or not, and having to rely on unfamiliar medical procedures and monitors to tell you how your body is functioning seemed to be a particularly difficult dilemma, carrying with it even more anxiety and distress. This combines with the suddenness and strangeness of being thrust into a medicalised experience of care, and came as a universal shock to these women.

\section{3) Importance of relationship with midwives}

Women discussed their experiences with their Lead Maternity Caregiver (LMC) in terms of how they felt cared for, listened to and engaged with. While many midwives were described in a positive light, several of the women described some disappointing experiences. Each of the women who had been hospitalised had previously dealt with LMC midwives who they felt had not engaged with them.

"I had a really bad time with my son before this pregnancy and the midwife was quite indifferent at a vulnerable time. It was really, really awful because I had a terrible time with him. I had had a great pregnancy and a great midwife but then she retired and then I had to find another one. I did find another one, but we never really connected and in the end it was terrible. It was a personality conflict I suppose-she was not very caring. She was a bit impatient. I was in hospital and had to have an assisted delivery. I had three degree tears and I was in shock after the birth after being in labour for three days and they needed to break his collarbone to get him out-she said I could have pushed him out if I wanted to. As soon as the baby was out she just left, see ya later kind of thing — she was gone. So I was exhausted and in shock that this information from her was just awful. Was really terrible for me to hear that. It has taken years for me to get over that birth" (Katie, twins, high blood pressure).

The same woman had a very different experience during her next pregnancy.
"Having lovely midwives made a massive difference — they were compassionate right from the outset. Very caring. When I was in hospital their contact withdrew a bit, but I was being looked after by hospital staff, but after I came out of hospital they piled on the support again and that was enormous. It was what I needed. I think they went a bit beyond" (Katie, twins, high blood pressure).

Women in the study described engaged midwives as partners who showed themselves to be trustworthy, supportive, and confidence building. Midwives who were accommodating and built strong supportive relationships with the women were appreciated. These midwives were also described as getting help when it was needed, having good listening skills, preparing the women for hospital and providing parenting advice after the child was born.

On the other hand, women felt disengaged from their midwives when the midwife was difficult to get hold of, didn't seem to care or seemed judgmental. At times they described personality clashes and arguments with the midwife. In these scenarios, women did not see their midwife as an advocate and felt unprepared for hospital and medical care.

\section{The women who had been in hospital described their contact with hospital doctors as distressing and anxiety provoking.}

\section{4) Interacting with hospital staff}

The women who had been in hospital described their contact with hospital doctors as distressing and anxiety provoking. The women were often provided with what could be termed rational/technical care (Benner, Tanner, \& Chelsa, 2009), and this was often recalled as adding to the women's stress levels.

\footnotetext{
"The dramatisation of the hospital-they are very factual, not very personable. It stresses you out even more" (Annamarie, high blood pressure).
}

"Explaining worst-case scenarios with technical information that you don't really understand-you feel anxious about everything. Doctors seem to be there to do a job-that's it" (Julie, heart condition).

"That was the hardest part about it. If you are doing all these tests, why don't you talk to me, ask me how I am feeling? They don't ask you how you are feeling. They just look at baby and it's their domain and oh yeah baby's got this, baby's got that, they didn't call it the baby-they called it the fetus most of the time and I said 'oh it's a boy' and they didn't care it was a boy or anything like that. It was an 'it' to them" (Claire, pre-eclampsialgestational diabetes).

"The anxiety is enormous, life and death is hanging in the balance-they do care, but they have such limited time tugging at them, they have to make a decision and move on. They have no time to dwell on your case" (Alison, potential preterm delivery).

Two of the women were told that their babies were at high risk of death when they were admitted to hospital.

"I had a severe kidney infection. I could hardly walk. I felt as if I had been kicked. I got scared when the staff at the hospital told me I might lose my baby. Being told I might lose the baby made me lose it" (Susan, potential preterm delivery).

"I was positive for listeria. I was told that is fatal for the kid so they wanted to induce immediately. I was 31 weeks-Oh that is too early! I was scared for the kids" (Katie, twins, potential preterm delivery).

Further stress was described when women felt uninformed regarding the medical and hospital procedures they were expected to undertake, or were unable to understand medical terminology.

"They seem to do things and then explain if you ask. You don't feel you can say no" (Pare, gestational diabetes). 
Women also found it hard to advocate for themselves in the hospital setting and felt particularly vulnerable. Husbands and midwives often became their advocates.

\section{"My husband advocated for me-in fact he insisted certain things got done" (Mary, potential preterm delivery).}

"My midwife was on the case-she would say she needs a scan or she needs this done or that done. She took charge. Like I remember she sat in the room there was a point when the babies were going to be born and they said we will have to send her to [a distant city] and she sat there with the doctors and said she is not going from [home city]. You are going to have to find space in NICU whether you like it or not and she is going to have them and they made space" (Anya, twins).

On the other hand, when technocratic, impersonal care was supplemented by humane care, which incorporated advocacy and support, women described a more engaged and positive experience. Hospital midwives were described in glowing terms by all six women-it was the midwives who gave reassurance and showed compassion.

"They are there for the love of people-they feel for you
and care for you and they will speak up for you" (Trish,
incompetent cervix).
"It felt really good to know someone was going to take away
all that anxiousness" (Freda, potential preterm delivery).

\section{5) Lessons learnt: Importance of support}

After discussing their experiences, women were asked "what advice would you give to pregnant women?" The question was frequently answered in terms of the support networks the women required and requested. While family was important, the crucial role of the midwife who was engaged and who demonstrated humane caring and understanding was also highlighted.

\section{"My husband was fantastic, but make sure you click with your midwife, it can make all the difference" (Annemarie, hyperemesis). \\ "My midwife told me I can do this. That confidence was all I needed-look for a midwife that can instil that confidence" (Jennifer, potential preterm delivery/high blood pressure).}

Many women said they had underestimated the importance of their midwife when first choosing one, but now, with experience of a pregnancy complication, saw this as a crucial role in their pregnancy, birth and beyond. Women also emphasised the need for the midwife to provide essential parenting advice and care attuned to their unique psychosocial needs.

\section{DISCUSSION}

The goal of this research was to understand the experiences of a group of women diagnosed with pregnancy complications and how they experienced their care. This research revealed the women we interviewed had high levels of distress in this situation, feeling out of control and overwhelmed, but contained and suppressed expression of their distress during the pregnancy in order to care for others and maintain a sense of control. As one participant put it, "I held it in and put on a brave face for my husband".

\section{Stress, disruption, and distress}

It was striking that all the women in this study, despite a wide variety of different medical conditions and experiences of care, spoke of how the unexpected, overwhelming experience of having a medical complication coloured and disrupted their experience of pregnancy. The expectation of a natural and healthy gestation was interrupted with fear, uncertainty, and helplessness. This mirrors the experiences described in a study of the mood of birthing by Crowther, Smythe and Spence (2014)—when a medical intervention is required, everything suddenly changes, and the sacred space of allowing nature to take its course is violated. For the pregnant women in our study, it was the sense of safety and confidence in the process of pregnancy that was shaken, leaving them emotionally stunned.

\section{Distancing}

Disconnection from emotions in a time of stress has been called "distancing" and has been described as an adaptive method of coping that can arise when the person feels helpless in the face of a stressful experience (Folkman \& Lazarus, 1988). Distancing may be adaptive in comparison to over-engagement with feelings or rumination (Kross \& Ayduk, 2011). Emotional distancing may reduce distress in the immediate crisis situation. When they were looking back, however, the real distance in time and place seemed to allow the women in this study to acknowledge and experience the feelings they needed to suppress at the time. This emotional distancing represents a challenge, though, to midwives caring for women during a medical illness. Though feeling terribly afraid and out of control, some women present a façade that functions both to protect others and to protect themselves from the intensity of the distress. It is not necessarily helpful to tear down this façadebut it also may be important to give permission to feel afraid, and to ask questions that allow the woman to open the door to her feelings if she wants to.

\section{Reassurance and support}

Women need reassurance that others understand their fears and worries (Kent, Yazbek, Heyns, \& Coetzee, 2015; Stainton, 1992). Stainton (1992) noted that mothers tend to be focused on possible good outcomes, while health professionals focus on possible problems. This can create a mismatch in expectations, with mothers perceived as denying the risks and health professionals as being irritating and catastrophising. This is consistent with our findings that some mothers in this study felt the emphasis of hospital doctors was on "life and death" and "dramatisation", and this increased their distress, while midwives were able to make them feel cared for and reassured by taking a more personal approach.

The midwife's knowledge, of her client and the supports and strengths available to her, is particularly important in deciding how to support and when to explain, and re-explain, complex medical information. Stainton (1992) suggested changing the language to reflect possibilities in situations of medical risk rather than focusing on worst-case scenarios, and this study supports the continued relevance of this advice. Optimism is a good predictor of adaptive functioning and outcomes (Barber \& Starkey, 2015), and should be supported as long as the women are doing what needs to be done to take care of themselves and their baby (McDonald, Kingston, Bayrampour, Dolan, \& Tough, 2014).

Women in this study emphasised the need to be prepared for dealing with the medical system and possible hospitalisation. Suggestions have been made that midwives, who recognise the early development of complications, can in turn assist women in preparing for the experience of dealing with the medical system (Berg \& Dahlberg, 2001). 


\section{Two ways of caring}

The women in this study discussed two very different types of care that they received from their health care professionals. Technocratic, impersonal care was distressing and disempowering. On the other hand, care which was technically sound, but also included humane attention to the women's feelings and provided advocacy and support was valued and remembered with gratitude. "Technique and narrow rational-technicality alone cannot address interpersonal and relational responsibilities, discernment, and situated possibilities required by caring for persons made vulnerable by illness and injury" (Benner, Tanner, \& Chelsa, 2009, p. xvi). This study supports the position that while technically expert care is necessary, it is not sufficient, and that humane care, advocacy and support can reduce anxiety and stress for women in high-risk situations.

Another important issue to recognise and acknowledge is the lack of control many women feel in these circumstances. Putting this into words can be helpful to regain some sense of control, and the midwife can work with the woman to identify where she can, and does, retain control of her self-care and other aspects of her life.

The inclusion and acknowledgment of the importance of partners, family, and other support people at this time may be key to combatting the feeling of being alone and helpless. Midwives may have knowledge of a woman's personal situation that other health professionals do not, and so they may be in the best position to facilitate involvement of family, clergy, and whatever other supports may be appropriate.

\section{Assessing psychological wellbeing}

Research has shown that it can be difficult for health care providers to accurately identify mental health issues in physical health settings (Dawes, Faust, \& Meehl, 2002). The midwifery literature has also described the dilemma of midwives who must appear calm and reassuring, while also juggling the need for risk monitoring (Scamell, 2011; Skinner, 2011). The task of assessing and supporting women's psychological well-being during a time of crisis is clearly a complex and demanding one, and requires a sensitive understanding of the woman and her family, and her style of dealing with distress. Since women may be hesitant to express their emotions at this time, it may be important to use mental health screening tools such as the Edinburgh Postnatal Depression Scale (Cox, Holden, \& Sagovsky, 1987), which can be utilised during pregnancy (Barber \& Starkey, 2015; Currie, 2012; Gibson, McKenzie-McHarg, Shakespeare, Price, \& Gray, 2009). Of course, this is not a panacea, and the foundation of sensitive assessment of a woman's emotional state is the relationship that has been built over time, in a safe and collaborative space, into which the midwife can bring her knowledge, wisdom, and support.

Women valued the responsiveness and availability of their LMCs, but those who were hospitalised also emphasised the important role of the core (hospital) midwives during a crisis point in their lives. In both roles, the holistic approach and attunement to the whole woman seems to be key.

The first competency of the Midwifery Council of New Zealand (Midwifery Council of New Zealand, 2004) articulates the notion of "being with" women. This concept incorporates partnership, responsiveness, and empowerment of women. The stories of these women, whose pregnancies were marked by medical procedures, worry, and disruptions of care, emphasise the importance of this competency, whether under the care of an LMC midwife or in the care of hospital staff.

\section{LIMITATIONS AND FUTURE DIRECTIONS}

In this small study, women volunteered for in-depth interviews. Perhaps women, who have a pregnancy they experience as traumatic, have a need to talk about it and tell their story, and this may lead them to volunteer, so the women described here may have been more distressed than the "average" woman who has a complicated pregnancy. The size of the sample at twelve also means that the range of pregnancy complications was not covered. The study was conducted in a single New Zealand region, and women who were hospitalised were from a single antenatal unit, so their experiences may not be representative of New Zealand women from different regions and circumstances.

This study outlines some issues that arise from medical complications from the perspectives of the women themselves; we did not speak with the partners of these women, and their experiences and perspectives would provide further insights. Similarly, it would be helpful to ask midwives, particularly those in the role of LMC, about what they see and what they do when their clients are faced with medical complications and with hospitalisation.

Further research might explore more how women with pregnancy complications understand the illness/medical event itself-what they know, where they get that information, and how they perceive their role in relation to the medical and maternity care systems. This might lead to advice, strategies, and interventions to improve communication between women and their health care providers at these often challenging times.

A further area for research that could be worth exploring is the decision-making process that women undertake in obtaining the services of a midwife and how prior experiences with maternity and medical care contribute to this important choice.

\section{CONCLUSIONS}

Midwives are in a unique position to assist women with pregnancy complications by translating medical jargon as well as providing emotional guidance and support. From the interviews in this study, it appears that an engaged midwife who provides humane comprehensive care, which incorporates advocacy and support, makes a difference and has the opportunity to assist in the amelioration of stress and anxiety for these women.

It is important for midwives to be aware that women in a medical crisis are likely to feel out of control, fearful, and confused. Some respond by containing their distress, so they appear to be coping well on the surface, but beneath there is turmoil. This presents a challenge for midwives and other health professionals caring for women. It is important to recognise the magnitude of the event for a woman and her family, and to seek to provide support and information in sensitive ways that can be taken in gradually. It may also be helpful to be aware of opportunities to increase the woman's sense of control over those aspects of her care and selfcare that can be controlled. Midwives provide care, information, and reassurance and this study suggests that midwives (both core and LMC) are vital to women's wellbeing in both normal and medically complicated pregnancies.

\section{ACKNOWLEDGEMENTS}

The authors would like to thank the women who told their stories. We are also grateful for the support of Marissa Panettiere, Lindsay Fergusson, and Simone DeGiorgio in this research, as well as the thoughtful comments of anonymous reviewers. This work was also supported in part by a summer research scholarship from the University of Waikato. The authors have no conflicts of interest to declare. 


\section{REFERENCES}

Barber, C.C. (2012). Prelude to parenthood: The impact of anxiety and depression during pregnancy. Perinatal Depression, Maria Graciela Rojas Castillo (ed). InTech: Rijeka, Croatia.

Barber, C. C., \& Starkey, N. J. (2015). Predictors of anxiety among pregnant New Zealand women hospitalised for complications and a community comparison group. Midwifery, 31(9), 888-896. doi:http:// dx.doi.org/10.1016/j.midw.2015.04.017

Benner, P., Tanner, C. A., \& Chelsa, C. A. (2009). Expertise in nursing practice: Caring, Clinical Judgement \& Ethics (2nd ed). New York: Springer Publishing Company

Berg, M., \& Dahlberg, K.. (2001). Swedish midwives' care of women who are at high obstetric risk or who have obstetric complications. Midwifery, 17(4), 259-266. doi:http://dx.doi.org/10.1054/ midw.2001.0284

Brandon, A. R., Pitts, S., Robinson, R., \& Stringer, C. A. (2007). Maternal and fetal representations, dimensions of personality, and prenatal attachment in women hospitalized with high-risk pregnancy. Journal of the American Psychoanalytic Association, 55(1), 253-259. doi:10.1037/0022-3514.61.2.226.

Brandon, A. R., Trivedi, M. H., Hynan, L. S., Miltenberger, P. D., Labat, D. B., Rifkin, J. B., \& Stringer, C. A. (2008). Prenatal depression in women hospitalized for obstetric risk. Journal of Clinical Psychiatry, 69(4), 635-643. doi:10.4088/JCP.v69n0417

Braun, V., \& Clarke, V. (2006). Using thematic analysis in psychology. Qualitative Research in Psychology, 3(2), 77-101. doi:http://dx.doi. org/10.1191/1478088706qp063oa

Breitkopf, C. R., Primeau, L. A., Levine, R. E., Olson, G. L., Wu, Z. H., \& Berenson, A. B. (2006). Anxiety symptoms during pregnancy and postpartum. Journal of Psychosomatic Obstetrics \& Gynecology, 27(3), 157-162. Retrieved from http://ezproxy.waikato.ac.nz/login?url=http:// search.proquest.com/docview/621611288? accountid $=17287$

Cox, J. L., Holden, J. M., \& Sagovsky, R. (1987). Detection of postnatal depression: Development of the 10-item Edinburgh Postnatal Depression Scale. The British Journal of Psychiatry, 150, 782-786. Retrieved from http://ezproxy.waikato.ac.nz/login?url=http://search. proquest.com/docview $/ 617443156$ ?accountid $=17287$

Crowther, S., Smythe, L., \& Spence, D. (2014). Mood and birth experience. Women and Birth, 27, 21-25. doi: 10.1016/j. wombi.2013.02.004

Currie, J.C.H. (2012). Perceptions and relationships of pregnant women and their midwives. Unpublished B.Soc Sc (Hons) Honours Dissertation, Waikato University, Hamilton.

Da Costa, D., Larouche, J., Dritsa, M., \& Brender, W. (1999).

Variations in stress levels over the course of pregnancy: Factors associated with elevated hassles, state anxiety and pregnancy-specific stress. Journal of Psychosomatic Research, 47(6), 609-621. Retrieved from http://ezproxy. waikato.ac.nz/login?url=http://search.proquest.com/docview/619435154 ?accountid $=17287$

Dawes, R. M., Faust, D., \& Meehl, P. E. (2002). Clinical versus actuarial judgment. New York, NY, US: Cambridge University Press.

Dunkel Schetter, C. (2009). Stress Processes in Pregnancy and Preterm Birth. Current Directions in Psychological Science, 18(4), 205-209. doi:http://dx.doi.org/10.1111/j.1467-8721.2009.01637.x

Dunkel Schetter, C. , \& Tanner, L. (2012). Anxiety, depression and stress in pregnancy: Implications for mothers, children, research, and practice. Current Opinion in Psychiatry, 25(2), 141-148. doi:10.1111/ j.1523-536X.2010.00441.x

Folkman, S., \& Lazarus, R. S. (1988). Coping as a mediator of emotion. Journal of Personality and Social Psychology, 54(3), 466-475. doi:10.1037/0022-3514.54.3.466

Gibson, J., McKenzie-McHarg, K., Shakespeare, J., Price, J., \& Gray, R. (2009). A systematic review of studies validating the Edinburgh Postnatal Depression Scale in antepartum and postpartum women. Acta Psychiatrica Scandinavica, 119(5), 350-364. doi:10.1111/j.16000447.2009.01363.x

Gray, B. A. (2006). Hospitalization history and differences in self-rated pregnancy risk. Western Journal of Nursing Research, 28(2), 216-229. Retrieved from http://ezproxy.waikato.ac.nz/login?url=http://search. proquest. com/docview/621159196?accountid $=17287$
Heaman, M., Gupton, A., \& Gregory, D. (2004). Factors influencing pregnant women's perceptions of risk. MCN: The American Journal of Maternal/Child Nursing, 29(2), 111-116. doi:10.1097/00005721200403000-00010

Kent, R. A., Yazbek, M., Heyns, T., \& Coetzee, I.. (2015). The support needs of high-risk antenatal patients in prolonged hospitalisation. Midwifery, 31(1), 164-169. doi:http://dx.doi.org/10.1016/j. midw.2014.08.003

King, N. M., Chambers, J., O'Donnell, K., Jayaweera, S. R., Williamson, C., \& Glover, V. A. (2010). Anxiety, depression and saliva cortisol in women with a medical disorder during pregnancy. Archives of Women's Mental Health, 13(4), 339-345. Retrieved from http://ezproxy. waikato.ac.nz/login?url=http://search.proquest.com/docview/606835800 ?accountid $=17287$

Kross, E., \& Ayduk, O. (2011). Making meaning out of negative experiences by self-distancing. Current Directions in Psychological Science, 20(3), 187-191. doi:10.1177/0963721411408883

Leeners, B., Stiller, R., Neumaier-Wagner, P., Kuse, S. M. D., Schmitt, A., \& Rath, W. (2008). Psychosocial distress associated with treatment of hypertensive diseases in pregnancy. Psychosomatics, 49(5), 413-419. doi:10.1001/jama.281.9.799

Leichtentritt, R. D., Blumenthal, N., Elyassi, A., \& Rotmensch, S. (2005). High-risk pregnancy and hospitalization: The women's voices. Health \& Social Work, 30(1), 39-47. Retrieved from http://ezproxy. waikato.ac.nz/login?url=http://search.proquest.com/docview/210560116 ?accountid $=17287$

Littleton, H. L., Bye, K., Buck, K., \& Amacker, A. (2010). Psychosocial stress during pregnancy and perinatal outcomes: A meta-analytic review. Journal of Psychosomatic Obstetrics \& Gynecology, 31(4), 219-228. doi:10. 3109/0167482X.2010.518776

McDonald, S. W., Kingston, D., Bayrampour, H., Dolan, S. M., \& Tough, S. C. (2014). Cumulative psychosocial stress, coping resources, and preterm birth. Archives of Women's Mental Health, 17(6), 559-568. doi:10.1007/s00737-014-0436-5

Melender, H-L., \& Lauri, S. (1999). Fears associated with pregnancy and childbirth - experiences of women who have recently given birth. Midwifery, 15(3), 177-182. doi:10.1016/S0266-6138(99)90062-1

Midwifery Council of New Zealand. (2004). The Competencies for Entry to the Register of Midwives. Wellington, New Zealand.

New Zealand College of Midwives Inc. (2016). Midwifery in New Zealand. Retrieved from://www.midwife.org.nz/in-new-zealand/ midwifery-in-new-zealand

Perlen, S., Woolhouse, H., Gartland, D., \& Brown, S. J. (2013). Maternal depression and physical health problems in early pregnancy: Findings of an Australian nulliparous pregnancy cohort study. Midwifery, 29(3), 233-239. doi:http://dx.doi.org/10.1016/j.midw.2012.01.005

Robinson, M., Pennell, C. E., McLeane, N. J., Oddy, W. H., \& Newnham, J. P. (2011). The over-estimation of risk in pregnancy. Journal of Psychosomatic Obstetrics \& Gynecology, 32(2), 53-58.

Scamell, M., (2011). The swan effect in midwifery talk and practice: A tension between normality and the language of risk. Sociology of Health \& Illness, 33(7), 987-1001. Retrieved from http://ezproxy.waikato.ac.nz/ login?url=http://search.proquest.com/docview/918748133?account id $=17287$

Skinner, J. (2011). Being with women with risk : The referral and consultation practices and attitudes of New Zealand midwives. New Zealand College of Midwives Journal, 45, 17-20.

Stainton, M. C. (1992). Mismatched caring in high-risk perinatal situations. Clinical Nursing Research, 1(1), 35- 49.

Stainton, M. C., Lohan, M., \& Woodhart, L. (2005). Women's experiences of being in high-risk antenatal care day stay and hospital admission. Australian Midwifery, 18(1), 16-20. doi:http://dx.doi. org/10.1016/S1448-8272(05)80014-8

\section{Accepted for publication June 2016}

Currie, J., \& Cornsweet Barber, C. (2016). Pregnancy gone wrong: Women's experiences of care in relation to coping with a medical complication in pregnancy. New Zealand College of Midwives Journal, 52, 35-40.

http://dx.doi.org/10.12784/nzcomjn152.2016.5.35-40 